\title{
KINERJA LAPANGAN PENUMPUKAN STASIUN JAKARTA GUDANG PT KERETA API INDONESIA
}

\author{
Fernaldi Anggadha Pratama ${ }^{1}$, Tri Mulyono ${ }^{2}$ \\ Email :_fernaldi.anggadha990@gmail.com ${ }^{1}$, trimulyono@unj.ac.id $^{2}$ \\ Prodi D III Transportasi, Fakultas Teknik - Universitas Negeri Jakarta \\ Prodi D III Transportasi, Fakultas Teknik - Universitas Negeri Jakarta
}

\begin{abstract}
Abstrak. Dengan menggumpulkan data dalam bentuk primer dan sekunder yaitu berupa Pengamatan langsung disekitar lapangan penumpukan Stasiun Jakarta gudang mengenai kapasitas lapangan penumpukan dalam bentuk cacatan tentang situasi dan kondisi di lapangan, melakukan wawancara langsung kepada pihak karyawan PT Kereta api Indonesia beserta pihak ekspeditur dan rekap bongkar muat bulan juni, yang dilakukan oleh penulis selama melakukan kegiatan Praktek kerja Lapangan (PKL). Data yang didapatkan tersebut kemudian dianalisis untuk mengetahui Yard Occupancy Ratio. Tingginya rata-rata penggunaan lapangan penumpukan yang tidak sesuai dengan kineja bongkar muat dan pengendapan petikemas yang tinggi dapat mempengaruhi Yard Occupancy Ratio itu sendiri. Dengan demikian Perlu melakukan pengawasan rutin di lapangan penumpukan dan mengetahui petikemas mana yang sudah melewati masa penimbunan di lapangan penumpukan Stasiun Jakarta gudang.
\end{abstract}

Kata Kunci: Kinerja, Lapangan penumpukan, bongkar muat, dan petikemas.

\begin{abstract}
Abstrac. By collecting data in primary and secondary forms, namely in the form of direct observation around the stacking field at the Jakarta warehouse station regarding the capacity of the piling field in the form of notes about the situation and conditions in the field, conducting direct interviews with employees of PT Kereta Api Indonesia and the forwarders and recap loading and unloading months June, which was carried out by the author during the Fieldwork Practices (PKL). The data obtained are then analyzed to determine the Yard Occupancy Ratio. The high average use of stacking yards that is not in accordance with the loading and unloading performance and high container deposition can affect the Yard Occupancy Ratio itself. Thus, it is necessary to carry out routine supervision in the stockpiling field and to find out which containers have passed the stockpiling period at the warehouse in Jakarta Station.
\end{abstract}

Keywords: Performance, yard, loading and unloading, and containers

\section{A. PENDAHULUAN}

Transportasi mempunyai peranan penting dalam mendukung pertumbuhan ekonomi, pengembangan wilayah dan pemersatu wilayah Negara Kesatuan Republik Indonesia dalam rangka mewujudkan Wawasan Nusantara, serta memperkukuh ketahanan nasional dalam usaha mencapai tujuan nasional berdasarkan Pancasila dan Undang-Undang Dasar Negara Republik Indonesia Tahun 1945. Suatu interaksi yang baik dan ideal antara komponen - komponen transportasi (penumpang,barang, sarana dan prasarana) membentuk suatu sistem transportasi yang komprehensif, efisien dan efektif sehingga diharapkan mampu mengoptimalkan fungsi transportasi dalam suatu kawasan perkotaan. Distribusi barang adalah elemen vital dalam kegaiatan pemasaran suatu barang. Suatu perusahaan sangat perlu melakukan distribusi, Menurut Tjiptono (2008) Distribusi merupakan suatu proses kegiatan pemasaran yang bertujuan untuk mempermudah kegiatan penyaluran barang atau jasa dari pihak produsen ke pihak konsumen. untuk menciptakan distribusi barang yang baik maka harus membutuhkan fasisitas yang baik agar proses pendistribusian barang tersebut dapat bergerak dengan lancar.

Lapangan penumpukan merupakan salah satu fasilitas yang digunakan untuk melayani bongkar muatan. Lapangan penumpukan peti kemas digunakan untuk menyimpan peti kemas setelah dibongkar ataupun yang akan dimuat. Lapangan penumpukan diperlukan untuk mencegah resiko delay yang mengakibatkan produksi bongkar muat menurun dan waktu kereta dan barang dipelabuhan menjadi lama. Lapangan penumpukan harus memiliki tanggung jawab dan kewajiban dalam memberikan kepuasan terhadap pengguna jasanya. Maka, sudah seharusnya lapangan penumpukan mampu mengelola semua sumber daya yang dimiliki agar menghasilkan kinerja yang baik.

Stasiun Jakarta gudang salah satu stasiun yang berusia cukup tua di Indonesia. Stasiun Jakarta gudang dikelola bersama oleh PT Kereta Api Indonesia Daerah Operasi I Jakarta dan PT KA Logistik (Kalog). Letaknya berada di Jalan Kampung Bandan, dan tidak jauh dari stasiun Kampung Bandan. Sejak dahulu, stasiun ini dipergunakan untuk memperlancar arus pengangkutan barang dari kawasan Kota ke Pelabuhan Tanjung Priok. Saat ini bangunan-bangunan stasiun Jakarta Gudang sudah direnovasi meskipun sebagian di antaranya masih asli. Istilah Kampung Bandan berarti perkampungan Rakyat Bandan yang menjadi tawanan tentara Belanda. Stasiun ini beroperasi untuk kereta angkutan 
barang, seperti peti kemas, parcel, paket barang, dan lain sebagainya. Kereta barang juga menerima pengiriman barangbarang elektronik seperti komputer dan televisi, dengan standar pengemasan yang disyaratkan oleh PT. KA Logistik. Selain itu, Kereta barang juga menerima pengiriman kendaraan baik bermotor maupun manual seperti sepeda dan sepeda motor.

Lapangan penumpukan Stasiun Jakarta gudang yang dikelolah PT Kereta Api Indonesia yang disewakan kepada pihak ekspedisi ini cukup baik, terutama dalam melayani pengguna jasanya. Untuk mengukur kinerja lapangan penumpukan biasanya diukur dari kinerja operasional atau kinerja selama kegiatan bongkar muat. Proses kegiatan bongkar muat membutuhkan fasilitas lapangan penumpukan yang memadai sebagai lokasi penumpukan petikemas sementara sebelum petikemas dimuat ke atas kereta ataupun diambil oleh pemilik barang. Dalam hal ini penulis akan membahas Yard Occupancy Ratio lapangan penumpukan di stasiun jakarta gudang PT Kereta Api Indonesia.

\section{B. METODE PENELITIAN}

Dalam pembahasan serta beberapa keterangan data yang diperlukkan untuk mengolahnya dalam penulisan karya ilmiah penulis menggunakan pendekatan secara analisis kualitatif, analisis kualitatif mengandung makna suatu penggambaran atas data dengan menggunakan kata dan baris kalimat. Penelitian ini menggunakan pendekatan kualitatif, bertujuan untuk memahami suatu situasi sosial, peristiwa, peran, interaksi dan kelompok. Data dan informasi yang digunakan dalam penelitian ini didapat dari observasi dan wawancara. Informasi yang didapat dari observasi langsung, cacatan wawancara, dan foto kegiatan. Informasi tersebut dalam bentuk dokumen dan catatan peristiwa yang diolah menjadi data.

\section{HASIL DAN PEMBAHASAN}

Berasarkan data yang diperoleh dari hasil observasi dan wawancara pihak PT Kereta Api Indonesia, pihak ekspeditur yang ada di stasiun Jakarta gudang. Maka penulis akan menghitung jumlah kapasitas lapangan penumpukan yang terpakain di lapangan penumpukan Stasiun Jakarta gudang.

Yard Occupancy Ratio (YOR) merupakan perbandingan kapasitas lapangan terhadap petikemas di lapangan. YOR adalah ukuran yang digunakan untuk memonitor utilisasi Container Yard (CY). Sering juga disebut Yard Storage Occupancy. Secara ringkas YOR menunjukkan berapa persen kapasitas tersedia terminal kita yang dimanfaatkan untuk penumpukan Peti Kemas per periode tertentu misalnya per hari, per minggu, per bulan atau per tahun.

Yard Occupancy Ratio/YOR telah melampaui batas standar utilisasi fasilitas sebesar 65\%, Otoritas Pelabuhan Utama Tanjung Priok dapat memindahkan barang yang waktu penumpukannya belum mencapai 3 hari dari lapangan penumpukan didalam pelabuhan ke lapangan penumpukan diluar pelabuhan.

Pengaruh YOR terhadap kondisi lapangan penumpukan.

1. YOR $<50 \%$ (Rendah)

YOR dibawah $50 \%$ menunjukkan terminal kita belum begitu berkembang.

2. YOR $60 \%$ s/d $69 \%$ (Sedang)

Beberapa kajian menunjukkan apabila YOR sudah lebih dari $60 \%$ dalam satu periode misal 1 tahun menunjukkan terminal sedang berkembang.Mulai perlu dipikirkan untuk mengatasi membludaknya Petikemas.

3. YOR $70 \%$ ke atas (Tinggi)

Kapasitas lapangan penumpukan sudah mulai mendekati batas maksimal pihak terkait sudah harus mempersiapkan lahan tambahan untuk limpahan petikemas berlebih.

Banyaknya petikemas di lapangan penumpukan berarti penggunaan lapangan penumpukan semakin mendekati kapasitas maksimal lapagan penumpukan. Untuk melancarkan arus petikemas dan pelayanan di lapangan penumpukan Stasiun Jakarta gudang PT. Kereta Api Indonesia harus memperhatikan keseimbangan YOR di lapangan penumpukan agar dapat berjalan dengan lancar.

kegiatan bongkar merupakan proses menurunkan barang dari kereta lalu menyusunnya di dalam lapangan penumpukan sedangkan muat proses memindahkan barang dari lapangan penumpukan lalu menaikannya ke atas kereta. Dalam kaitannya dengan kapasitas lapangan penumpukan PT Kereta Api Indonesia adalah proses kegiatan bongkar petikemas dari kereta menuju lapangan penumpukan dapat membuat kapasitas lapangan penumpukan semakin padat, sedangkan proses kegiatan muat petikemas dari lapangan menuju ke atas kereta dapat menurunkan tingkat pemakaian lapangan terhadap kapasitas lapangan penumpukan. Semakin besar jumlah bongkaran maka semakin meningkat juga pemakaian kapasitas lapangan penumpukannya. begitu pun sebaliknya semakin banyak kegiatan muat maka akan semakin mengurangi kapasitas lapangan penumpukan yang ada pada lapangan penumpukan tersebut.

Jumlah petikemas yang masuk maupun yang keluar dari lapangan penumpukan Stasiun Jakarta gudang dapat dilihat pada diagram yang telah di buat dibawah, Data petikemas yang masuk meliputi kegiatan bongkar muat petikemas dengan jumlah rangkaian rata-rata 30 gerbong datar. 


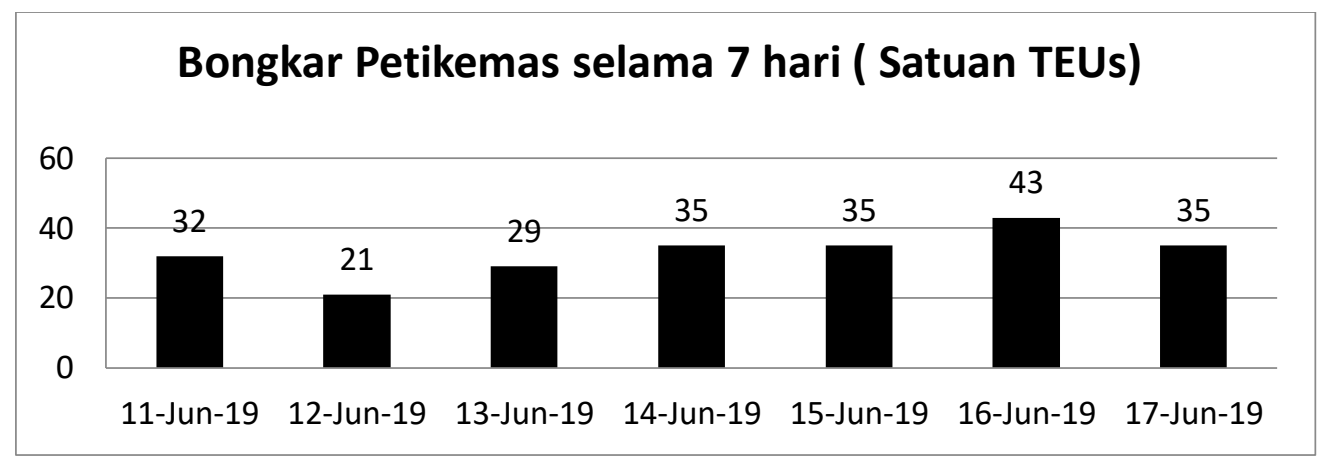

Gambar 1 Bongkar Muat Petikemas Selama 7 Hari

Gambar di atas adalah diagram jumlah petikemas yang dibongkar ke atas kerata. Data diambil selama tujuh hari pada tanggal 11 Juni 2019 sampai 17 Juni 2019, dari jumlah borngkar petikemas diatas dapat diketahui pada tanggal 16 Juni 2019 merupakan kegiatan bongkar tertingggi yaitu 43 Teus dengan total keseluruhan 229 Teus.

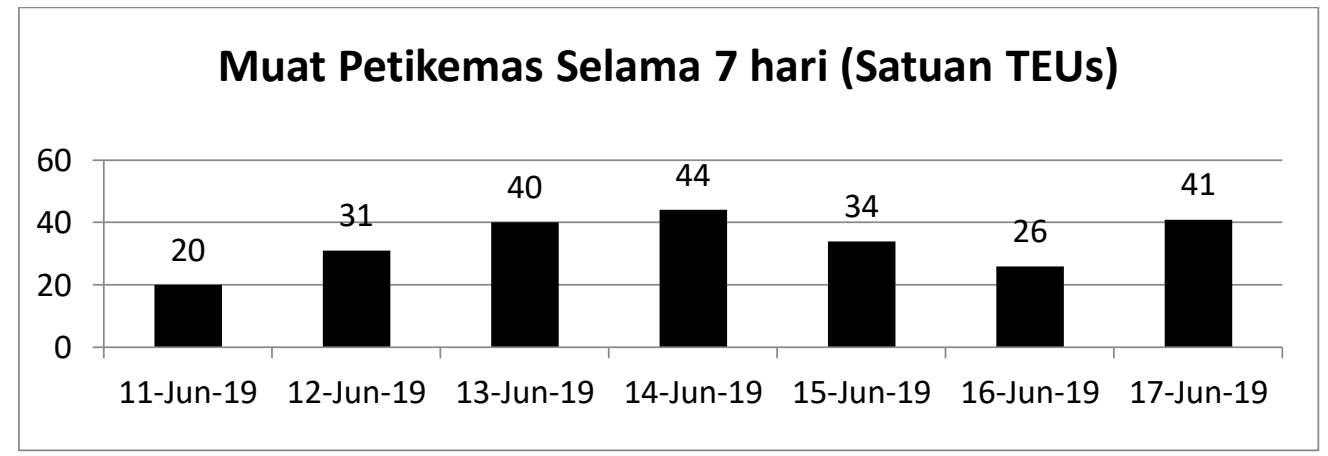

\section{Gambar 2 Muat Petikemas Selama 7 hari}

Gambar di atas adalah diagram jumlah petikemas yang dibongkar ke atas kerata. Data diambil selama tujuh hari pada tanggal 11 Juni 2019 sampai 17 Juni 2019, dari jumlah borngkar petikemas diatas dapat diketahui pada tanggal 14 Juni 2019 merupakan kegiatan bongkar tertingggi yaitu 44 Teus dengan total keseluruhan 236 Teus.

\begin{tabular}{|c|c|c|c|c|}
\hline \multicolumn{5}{|c|}{ Pemakaian lapangan penumpukan selama 7 hari } \\
\hline Hari & $\begin{array}{c}\text { Kapasitas } \\
\text { terpakai }\end{array}$ & Bongkar (+) & Muat (-) & $\begin{array}{c}\text { Total } \\
\text { Petikemas } \\
\text { (TEUs) }\end{array}$ \\
\hline 1 & 344 & 32 & 20 & 356 \\
\hline 2 & 356 & 21 & 31 & 346 \\
\hline 3 & 345 & 28 & 40 & 334 \\
\hline 4 & 334 & 35 & 44 & 335 \\
\hline 5 & 335 & 35 & 34 & 325 \\
\hline 6 & 325 & 43 & 26 & 342 \\
\hline 7 & 342 & 35 & 41 & 336 \\
\hline
\end{tabular}

Gambar 3 Pemakaian lapangan penumpukan selama 7 hari

Tabel diatas merupakan pemakaian lapangan penumpukan selama 7 hari, dengan pemakaian lapangan penumpukan tertinggi pada hari pertama mencapai 356 Teus dan pemakaian kapasitas terendah pada hari ke 5 mencapai 325 Teus.

Diketahui nilai YOR pada suatu lapangan penumpukan perhitungan jumlah petikemas yang ada di lapangan penumpukan dihasilkan dari kegiatan yang terjadi pada lapangan penumpukan itu sendiri. 
Grafik presentasi nilai YOR pada lapangan penumpukan Stasiun Jakarta gudang PT Kereta Api Indonesia dapat dilihat pada gambar dibawah, presentase penggunaan lapangan penumpukan selama 7 hari dibawah ini.

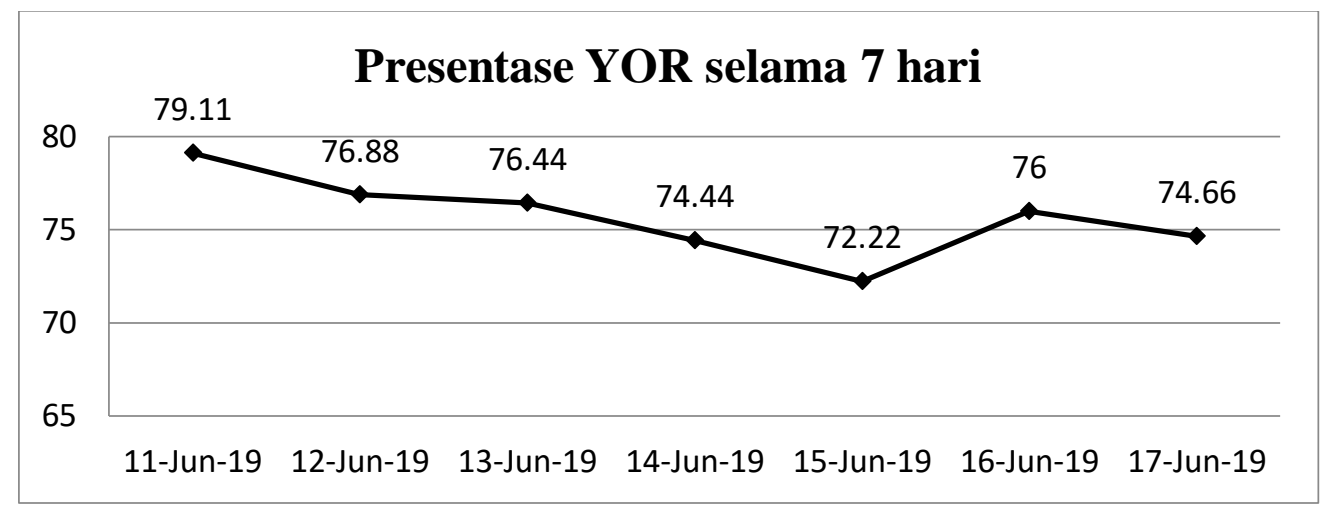

Gambar 4 Presentase YOR selama 7 hari

Dari gambar grafik di atas dapat diketahui bahwa pada tujuh hari pemakaian lapangan penumpukan, persentasi YOR cukup tinggi hingga melebihi batas standar. Persentase pemakaian lapangan penumpukan tertinggi ada pada tanggal $11,12,16$ yang mencapai angka $76,44 \%$ sampai $79,11 \%$ atau hampir mendekati angka maksimal. Kemudian bila dihitung persentase rataa-rata pada pada 7 hari pemakaian lapangan penumpukan di Stasiun Jakarta gudang sebesar 75,58\%, artinya rata-rata persentase YOR tinggi.

Faktor penyebab pemakaian lapangan penumpukan mendekati batas maksimal terjadi pada penumpukan petikemas terlalu lama, hal ini biasanya terjadi di Lapangan Penumpukan Stasiun Jakarta gudang petikemas melebihi masa yang ditetapkan terhitung dari petikamas yang di timbun di lapangan penumpukan yaitu 3 hari. Pemilik barang tidak bisa melakukan pemuatan ke atas kereta dikarenakan lama waktu petikemas ditimbun dilapangan penumpukan di pemberangkatan awal Stasiun Jakarta gudang dan Stasiun akhir Kalimalang untuk penimbunan petikemas selama 3 hari sampai 5 hari tidak dikenakan biaya.

Akibat yang terjadi jika pemakaian lapangan penumpukan mendekati batas maksimal. berkaitan dengan tingginya pemakaian lapangan penumpukan, terdapat hambatan yang timbul dikibatkan oleh kapasitas lapangan penumpukan yang mendekati batas maksimal. apabila penggunaan lapangan penumpukan melebihi standar atau bahkan melebihi kapasitas yang teredia akan mengakibatkan.

a. Kapasitas lapangan penumpukan yang tidak sesuai dengan kinerja bongkar muat dan pengendapan petikemas yang tinggi dapat mempengaruhi nilai YOR itu sendiri.

b. Penempatan petikemas yang tidak sesuai pada tempatnya dimana petikemas yang biasanya ditempatkan di lapangan penumpukan masing masing maka sekarang harus memanfaatkan segala ruang, dekat rel kereta , dekat tempat parkir mobil membongkar dan memuat muatan koli yang akan dimasukan ke petikemas.

\section{KESIMPULAN}

Berdasarkan dari permasalahan yang terdapat dilapangan serta dilengkapi dengan data-data pendukung, maka kesimpulan yang dapat ditarik yaitu:

1. Rata-rata pemakaian lapangan penumpukan selama 7 hari yaitu $75,58 \%$. persentase YOR tertinggi yaitu pada tanggal 15,16,17 mencapai angka 76,44\% sampai 79,11\% dengan penggunaan lapangan penumpukan yang tinggi.

2. Faktor yang menyebabkan tingginya pemakaian lapangan penumpukan yaitu Penumpukan petikemas terlalu lama, hal ini terjadi di Lapangan Penumpukan Stasiun Jakarta gudang. petikemas melebihi masa yang ditetapkan terhitung dari petikamas yang di timbun di lapangan penumpukan yaitu 3 hari dan tidak dikenakan biaya.

3. Kapasitas lapangan penumpukan yang tidak sesuai dengan masa pengendapan petikemas dalam hal ini melebihi masa penumpukan dapat mempengaruhi nilai YOR itu sendiri

\section{E. SARAN}

Berdasarkan uraian diatas, saran yang dapat diberikan agar proses bongkar muat tidak tidak memakan waktu lama, yaitu:

1. Perusahaan menerapkan tarif untuk penimbunan petikemas yang telah melebihi masa 3 hari di lapangan penumpukan Stasiun Jakarta gudang.

2. Perlu melakukan pengawasan rutin di lapangan penumpukan dan mengetahui petikemas mana yang sudah melewati masa penimbunan di lapangan penumpukan Stasiun Jakarta gudang.

\section{F. DAFTAR PUSTAKA}

Data - Pengertian, Fungsi, Jenis, Sifat, Sumber, Pengumpulan, Pengukuran, Sumber, Para Ahli. (2019, Juni 30). gurupendidikan. Dipetik Juli 05, 2019, dari gurupendidikan.co.id: https://www.gurupendidikan.co.id/data/ 
Divisi Angkutan Barang Stasiun Jakarta gudang. (2019, Juli 5). WTT Bulan Juni 2019. Jakarta, DKI Jakarta, Indonesia.

Objek dan metode penelitian. (2019). elib.unikom. Dipetik Juli 7, 2019, dari elib.unikom.ac.id: elib.unikom.ac.id/files/disk1/705/jbptunikompp-gdl-silviaperm-35211-6-unikom_s-i.pdf

Pengertian Data dan Jenis Data Penelitian (Primer / Skunder). (2019). bospengertian. Dipetik Juni 30, 2019, dari bospengertian.com: http://bospengertian.com/pengertian-data-adalah/

Pengertian Distribusi Secara Umum dan Menurut Para Ahli. (2014, Maret 7). vauzidotnet. Dipetik Juni 19, 2019, dari vauzidotnet.wordpress.com: vauzidotnet.wordpress.com/2014/03/07/pengertian-distribusi-secaraumum-dan-menurut-para-ahli/

Pengertian Kinerja Menurut Para Ahli. (2014, Desember 5). trigonalmedia. Dipetik Juni 21, 2019, dari trigonalmedia.com: https://www.trigonalmedia.com/2014/12/pengertian-kinerja-menurut-para-ahli.html

Peraturan Menteri Perhubungan Republik Indonesia Nomor PM 117 Tahun 2015. (2015). Pemindahan Barang Yang Melewati Batas Waktu Penumpukan (Long Stay) di Pelabuhan Tanjung Priok. Jakarta, DKI Jakarta, Indonesia.

Pemerintah Republik Indonesia Nomor 51 Tahun 2002. (2002). PERATURAN PEMERINTAH REPUBLIK INDONESIA NOMOR 51 TAHUN 2002 TENTANG. Jakarta: Republik Indonesia.

Petikemas Kramadibrata. (2017). eprints.umm. Dipetik Juni 23, 2019, dari eprints.umm.ac.id: http://eprints.umm.ac.id/35385/3/jiptummpp-gdl-mufidatulr-49465-3-babii.pdf

Standar Operasional Prosedur Tanggap Darurat Gangguan Operasional Kereta Api. (2018, Desember 12). Peraturan Direksi PT Kereta Api Indonesia. Bandung, Indonesia.

Stasiun Jakarta Gudang. (2015, oktober 20). kereta-api. Dipetik juni 19, 2019, dari kereta-api.info: https://kereta-api.info/stasiun-jakarta-gudang-2-4942.htm

Undang-Undang Nomor 23 Tahun 2007 Tentang Perkeretaapian. (2007). Undang-undang Nomor 23 Tahun 2007 Tentang Perkeretaapian. Jakarta: Indonesia.

Yard Occupancy Ratio, bumn.go.id. (2008, Juli 23). bumn. Dipetik Juli 11, 2019, dari bumn.go.id: http://www.bumn.go.id/pelindo1/berita/504 